\title{
Clinical profile and outcome of patients with severe sepsis treated in an intensive care unit in India
}

\author{
T T S Paary ${ }^{1}$, M S Kalaiselvan ${ }^{1}$, M K Renuka ${ }^{1}$, A S Arunkumar ${ }^{1}$ \\ (Index words: severe sepsis, septic shock, India, intensive care setting)
}

\begin{abstract}
Introduction Sepsis is the leading cause of intensive care unit (ICU) admissions and is associated with high mortality.

Objectives To identify the incidence, risk factors and outcome of patients with severe sepsis and septic shock.

Methods A prospective observational study was done in a multidisciplinary ICU over a period of 18 months. We included all adult patients admitted to ICU with features of severe sepsis and septic shock as per SCCM/ACCP guidelines. Data related to demography, co-existing illnesses, parameters to assess Acute Physiology and Chronic Health Evaluation (APACHE) II and Sequential Organ Failure Assessment (SOFA) scores, other relevant laboratory data, source of infection, organ failures and supportive measures given were recorded. Primary outcome data on mortality was collected and secondary outcome data on ventilator days, ICU length of stay (ALOS) and ventilator free days were recorded.
\end{abstract}

Results A total of 1162 patients were screened and 356 patients had severe sepsis. Incidence of severe sepsis was $30.6 \%$ and mortality rate was $51.6 \%$. APACHEII $(23.37 \pm 9.47)$ and SOFA $(7.58 \pm 4.05)$ scores at admission were high. Most common source of infection was from the respiratory tract $(37.2 \%)$ followed by urinary tract $(10.3 \%)$ and intra-abdominal $(9.5 \%)$ infections. About $63 \%$ of patients required ventilator support, $25.5 \%$ of patients required vasopressor support despite adequate fluid resuscitation and one third of patients required renal replacement therapy (35.7\%). Haematocrit, total leucocyte count, serum bilirubin and SOFA scores were significantly higher among non-survivors.

Conclusions Incidence of severe sepsis was high and was associated with a poor patient outcome in an ICU in India.

Ceylon Medical Journal 2016; 61: 181-184

http://doi.org/10.4038/cmj.v61i4.8386

${ }^{1}$ Sri Ramachandra University Reasearch Institute, India. 1 June 2016. and reproduction in any medium, provided the original author and source are credited.

\section{Introduction}

Sepsis is a common cause of admissions to intensive care units (ICU). Severe sepsis and septic shock contribute to significant morbidity and mortality in ICU patients. The mortality rate of sepsis ranges from $30-40 \%$ [1-3]. Despite advances over the past two decades, mortality in sepsis remains unchanged [4,5].

Sepsis is a systemic, deleterious host response to infection leading to severe sepsis (acute organ dysfunction secondary to documented or suspected infection) and septic shock (severe sepsis and hypotension not reversed with fluid resuscitation). Pathophysiology of sepsis is complex and multifactorial. Infection triggers pro-inflammatory and anti-inflammatory response that contribute to the control of infection as well as the tissue damage that lead to organ failure. Patient response to sepsis is dependent on characteristics of both the host (co-morbidities and immunosuppression) and the pathogen (virulence and organism load). Endothelial damage leads to coagulation abnormalities, such as intravascular coagulation, fibrinolysis, microvascular thrombi, and impaired tissue oxygenation. Vasodilation and hypotension lead to tissue hypoperfusion and decreased tissue oxygenation leading to organ failure.

Most of the available data related to incidence and outcome of sepsis are from Western countries. In contrast to Western countries where Gram-negative sepsis is the predominant cause of sepsis, tropical infections like dengue, malaria, leptospirosis, enteric fever and tuberculosis are also important causes of severe sepsis/ septic shock in India. The reported mortality of severe sepsis is over $50 \%[6,7]$. We conducted a prospective study to identify the profile and outcome of patients with severe sepsis admitted to the ICU of a tertiary care hospital in India. 


\section{Methods}

This was a prospective observational study conducted from June 2013 to December 2014. We admit critically ill unstable patients, who require intensive treatment and stable patients who require intensive monitoring to the ICU. All patients over 18 years of age admitted to the ICU were screened for severe sepsis and septic shock at admission or during their ICU stay as defined by SCCM/ ACCP criteria [8].

Severe sepsis was defined as sepsis and sepsisinduced organ dysfunction or tissue hypoperfusion [9]. Septic shock was defined as sepsis-induced hypotension persisting despite adequate fluid resuscitation [10]. Patients with severe sepsis/septic shock were included in our study. We excluded patients who died within 24 hours of admission to the ICU and those readmitted to the ICU during the same hospital stay. Our ICU is staffed with a full time intensivist and has access to facilities such as hemodialysis, imaging (CT, MRI and ultrasonography) and all blood investigations. All patients were managed according to standard sepsis management protocols including initial fluid resuscitation. Subsequent fluid administration was based upon central venous pressure measurement, lactate clearance and urine output. Early empiric broad spectrum antibiotics were started and organ support was given as required. Data related to demography, co-existing illnesses, parameters to assess Acute Physiology and Chronic Health Evaluation (APACHE) II and Sequential Organ Failure Assessment (SOFA) scores and other relevant laboratory data were collected. Data regarding the source of infection and supportive measures given were recorded. Primary outcome data related to morta-lity and secondary outcome data on ventilator days, ICU length of stay (LOS) and ventilator free days were collected.

Values for continuous data were expressed as mean \pm $\mathrm{SD}$ and categorical variables as proportions. Continuous variables with normal distribution were compared using Student $t$ test while those not normally distributed were analysed using Mann Whitney $U$ test. Categorical data were analysed using Chi-square test. Multivariate logistic regression models were used to determine predictors of mortality. Approval for the study was obtained from the Ethics Review Committee of the Institute.

\section{Results}

A total of 1162 patients were screened and 410 were selected according to inclusion criteria. Of these 410 patients, 30 patients died within 24 hours (mortality rate for first 24 hours was $7.3 \%$ ) of ICU admission and 24 patients were readmitted to ICU. These 54 patients were excluded from analysis. Data of 356 patients were analysed, of which majority were males (64.2\%). Mean age of these patients was 54 ( \pm 17 SD) years. Most common co-existing illnesses were hypertension (42\%), type II diabetes mellitus (42\%) and chronic kidney disease (25\%) (Table 1). The mean APACHEII (23.37 \pm 9.47$)$ and SOFA $(7.58 \pm 4.05)$ scores at admission were high (Table 2). About $63 \%$ of patients required ventilator support, $25.5 \%$ of patients required vasopressor support after adequate fluid resuscitation. One third (35.7\%) of patients required renal replacement therapy (Table 3)

Table 1. Patient characteristics

\begin{tabular}{|c|c|c|c|c|}
\hline & $\begin{array}{l}\text { All patients } \\
(n-356)\end{array}$ & $\begin{array}{l}\text { Survivors } \\
(n-172)\end{array}$ & $\begin{array}{l}\text { Non-survivors } \\
(n-184)\end{array}$ & p-value \\
\hline \multicolumn{5}{|l|}{ Demography } \\
\hline Age (mean \pm SD) & $54 \pm 17$ & $52.8 \pm 17.39$ & $57.9 \pm 16.24$ & 0.28 \\
\hline Male (\%) & $232(64.2 \%)$ & $110(63.9 \%)$ & $122(66.3 \%)$ & 0.36 \\
\hline Female (\%) & $124(34.8 \%)$ & $62(36.1 \%)$ & $62(33.7 \%)$ & 0.34 \\
\hline \multicolumn{5}{|l|}{ Co-existing illness } \\
\hline Hypertension (\%) & $152(42.6 \%)$ & $68(39.5 \%)$ & $84(45.6 \%)$ & 0.28 \\
\hline Diabetes mellitus (\%) & $150(42.1 \%)$ & $76(44.1 \%)$ & $74(40.2 \%)$ & 0.45 \\
\hline Chronic kidney disease (\%) & $90(25.2 \%)$ & $38(22 \%)$ & $52(28.2 \%)$ & 0.22 \\
\hline Coronary artery disease $(\%)$ & $24(6.7 \%)$ & $10(5.8 \%)$ & $14(7.6 \%)$ & 0.53 \\
\hline Liver disease $(\%)$ & $28(7.8 \%)$ & $14(8.1 \%)$ & $14(7.6 \%)$ & 0.50 \\
\hline Chronic obstructive airway disease (\%) & $12(3.3 \%)$ & $8(4.6 \%)$ & $4(2.19 \%)$ & 0.24 \\
\hline Malignancy (\%) & $10(2.8 \%)$ & $2(1.1 \%)$ & $8(4.3 \%)$ & 0.1 \\
\hline \multicolumn{5}{|l|}{ Vital parameters } \\
\hline Heart rate (beats/min) $($ mean $\pm \mathrm{SD})$ & $104.30 \pm 22.2$ & $100 \pm 21.4$ & $108 \pm 23.4$ & 0.06 \\
\hline Mean arterial pressure mmhg (mean $\pm \mathrm{SD})$ & $84.9 \pm 22$ & $89.7 \pm 20$ & $80 \pm 21$ & 0.08 \\
\hline
\end{tabular}




\begin{tabular}{|c|c|c|c|c|}
\hline & $\begin{array}{l}\text { All patients } \\
(n-356)\end{array}$ & $\begin{array}{l}\text { Survivors } \\
(n-172)\end{array}$ & $\begin{array}{l}\text { Non-survivors } \\
(n-184)\end{array}$ & p-value \\
\hline \multicolumn{5}{|l|}{$\begin{array}{l}\text { Laboratory parameters } \\
(\operatorname{mean} \pm \mathrm{SD})\end{array}$} \\
\hline Haematocrit (\%) & $33.30 \pm 6.2$ & $34.90 \pm 5.14$ & $31.8 \pm 6.7$ & 0.04 \\
\hline Total leucocyte count (cells/ $\mu$ l) & $15151 \pm 7798$ & $13811 \pm 6542$ & $16403 \pm 8643$ & 0.05 \\
\hline $\mathrm{PaO} 2 /$ Fio2 ratio $($ mean $\pm \mathrm{SD})$ & $307.1 \pm 88.54$ & $324.40 \pm 79.70$ & $294 \pm 93.9$ & 0.07 \\
\hline Serum creatinine $(\mathrm{mg} / \mathrm{dl})$ & $2.48 \pm 1.97$ & $2.25 \pm 1.9$ & $2.7 \pm 1.97$ & 0.03 \\
\hline Serum bilirubin (mg/dl) & $3.76 \pm 7.35$ & $2.30 \pm 4.70$ & $5.1 \pm 8.9$ & 0.00 \\
\hline Serum lactate $(\mathrm{mmol} / \mathrm{dl})$ & $3.30 \pm 2.06$ & $2.76 \pm 1.36$ & $3.8 \pm 2.4$ & 0.00 \\
\hline
\end{tabular}

Table 2. Severity of illness and patient outcomes

\begin{tabular}{lllll}
\hline & $\begin{array}{l}\text { All patients } \\
(n-356)\end{array}$ & $\begin{array}{l}\text { Survivors } \\
(n-172)\end{array}$ & $\begin{array}{l}\text { Non-survivors } \\
(n-184)\end{array}$ & $p$-value \\
\hline APACHE II $^{1}$ & $23.37 \pm 9.47$ & $19.80 \pm 8.7$ & $26.60 \pm 8.9$ & $<0.005$ \\
SOFA $^{2}$ & $7.58 \pm 4.05$ & $5.70 \pm 3.4$ & $9.30 \pm 3.7$ & $<0.005$ \\
Ventilator days & $2.91 \pm 3.03$ & $2.24 \pm 2.73$ & $3.53 \pm 3.18$ & $<0.005$ \\
Ventilator free days & $1.73 \pm 2.00$ & $2.78 \pm 1.97$ & $0.75 \pm 1.47$ & 0.024 \\
ICU LOS $^{3}$ & $4.60 \pm 3.46$ & $5.02 \pm 3.43$ & $4.20 \pm 3.45$ & \\
\hline
\end{tabular}

'APACHE II - Acute Physiology and Chronic Health Evaluation

${ }^{2}$ SOFA - Sequential Organ Failure Assessment

${ }^{3}$ ICU LOS - Length of stay in ICU

Table 4. Organ support requirement among survivors and non-survivors

\begin{tabular}{llllc}
\hline & $\begin{array}{l}\text { All patients } \\
(n-356)\end{array}$ & $\begin{array}{l}\text { Survivors } \\
(n-172)\end{array}$ & $\begin{array}{l}\text { Non-survivors } \\
(n-184)\end{array}$ & $p$-value \\
\hline Ventilator support (\%) & 62.9 & 57 & 68.5 & 0.01 \\
Vasopressor requirement (\%) & 25.50 & 12.8 & 41.3 & $<0.005$ \\
Steroids (\%) & 13.4 & 7 & 20.4 & $<0.005$ \\
Renal replacement therapy (\%) & 35.70 & 29.1 & 41.8 & 0.01 \\
\hline
\end{tabular}

Overall mortality among patients with severe sepsis/ septic shock was $51.6 \%$. Most common source of infection was from respiratory tract $(37.2 \%)$ followed by urinary tract $(10.3 \%)$ and intra-abdominal (9.5\%) site (Table 4). Demographic profile and co-existing illnesses among survivors and non-survivors were similar, however APACHEII (26.60 \pm 8.9 vs $19.80 \pm 8.7)$ and SOFA $(9.30 \pm 3.7$ vs $5.70 \pm 3.4)$ scores were significantly higher among non-survivors (Table 2). Total leucocyte count, serum creatinine, serum bilirubin and serum lactate levels were higher among non-survivors compared to survivors (Table 2).

Non-survivors required significantly higher organ support compared to survivors (Table 3). Univariate ana-lysis predicted multiple risk factors for mortality, but multivariate analysis identified high SOFA scores as a risk factor for mortality in severe sepsis/septic shock (Table 2).

\section{Table 3. Source of infection}

\begin{tabular}{lr}
\hline Site of infection & $\%$ \\
\hline Respiratory tract & 37.2 \\
Genito-urinary tract & 10.3 \\
Intra-abdominal & 9.5 \\
Primary bacteraemia & 8.1 \\
Skin and soft tissue & 7.0 \\
Device related & 3.9 \\
Central nervous system & 2.8 \\
Mixed infection & 9.2 \\
Other /undetermined & 12 \\
\hline
\end{tabular}

\section{Discussion}

In this prospective observational study we aimed to find the clinical profile and outcome of septic patients admitted to ICU. About $65 \%$ of our study population were 
men which was higher when compared to previous Indian studies [7]. Our patients were relatively young with a mean age of 54 years when compared to previous studies from Australia (60.7 years) and Germany (67 years) $[2,11]$. The incidence of severe sepsis in our patients was $30.6 \%$. Previous studies report varying proportions ranging from $8.4 \%$ to $27.1 \%$ [3,13-15]. Most common coexisting illnesses among our patients were hypertension (42\%) and type II diabetes mellitus (42\%), which was higher than reported before [7]. Strikingly our study population had $25 \%$ patients with chronic kidney disease when compared to $1.5 \%$ and $4.4 \%$ reported before $[3,12]$.

Most common source of infection in our study was the respiratory tract $(37 \%)$. Source of infection reported in different studies vary $[2,11,12]$. Of the 356 patients, $62.9 \%$ of patients required mechanical ventilation, which was lower than the rates reported before $(79.8 \%-89 \%)$ $[7,11,12]$. The reason for lower incidence of mechanical ventilation in our patients compared to other studies might be the low incidence of respiratory tract infection which was $37 \%$ in our study compared to others ( $43 \%$ to $84 \%$ ) $[7,11,12]$.

Mortality of our patients with severe sepsis was $51.6 \%$, which was comparable to $55.3 \%$ and $57.6 \%$ of previous two Indian studies $[6,7]$. When we compared our mortality rates was similar to a German study (48.4\%) [11]. However lower mortality rates have been reported from Australia and France which were 26.5\% and 35\% respec-tively $[2,3]$. We identified multiple risk factors for predictors of mortality on univariate analysis, but multivariate ana-lysis identified high SOFA score as a risk factor for mor-tality in severe sepsis/septic shock. Previous studies have identified renal failure as a significant risk factor for mortality, but our study did not find renal failure as a predictor of mortality, the probable reason being the case mix of our population, where patients with chronic kidney disease contributed to $25 \%$ of our ICU admissions [3, 7].

Our study has several limitations. We did not look at the microbiological data, usage of antibiotics, timing of starting antibiotics and appropriateness of antibiotics. Furthermore we do not have data on lead time and the events leading to ICU admission. In conclusion, incidence of severe sepsis was high among ICU admissions and they have a high mortality. Higher SOFA scores at admission were associated with higher mortality in severe sepsis/ septic shock.

\section{Conflicts of interest}

There are no conflicts of interest.

\section{References}

1. Angus DC, Linde-Zwirble WT, Lidiker, et al. J Epidemiology of severe sepsis in the United States: Analysis of incidence, outcome and associated cost of care. Crit Care Med 2001; 29: $1309-10$.
2. Simon F, Rinaldo B, Jeffrey L, et al. Adult-population incidence of severe sepsis in Australian and New Zealand intensive care units. Intensive Care Med 2004; 30: 589-96.

3. Brun-Buisson C, Meshaka P, Pinton P, Vallet B. EPISEPSIS: a reappraisal of the epidemiology and outcome of severe sepsis in French intensive care units. Intensive Care Med 2004; 30: 580-8.

4. Kirsi-Maija K, Michael B, Satoshi S, David P, Rinaldo B. Mortality Related to Severe Sepsis and Septic Shock Among Critically Ill Patients in Australia and New Zealand, 20002012. JAMA 2014; 311: 1308-16.

5. Aberegg SK, Richards DR, O’Brien JM. Delta inflation: a bias in the design of randomized controlled trials in critical care medicine. Crit Care 2010; 14: R77.

6. Todi S, Chattarjee S, Bhattacharyya M. Epidemiology of severe sepsis in India. Crit Care 2007; 11(Supp 2): 65.

7. Anant M, Prajowl S, Randeep G, Ravindra M, Naveet W. Development of a mortality prediction formula due to sepsis/ severe sepsis in a medical intensive care unit. Lung India 2015; 32: 313-9.

8. ACCP/SCCM Consensus Conference Committee: Definition for sepsis and organ failure and guidelines for the use of innovative therapies in sepsis. Crit Care Med 1992; 20: 864-74.

9. Levy MM, Fink MP, Marshall JC, et al. SCCM/ESICM/ ACCP/ATS/SIS. International Sepsis Definition Conference. Intensive Care Med 2003; 29: 530-8.

10. Dellinger R, Levy MM, Carlet JM, et al. International Surviving Sepsis Campaign Guidelines Committee: Surviving sepsis campaign: International guidelines for management of severe sepsis and septic shock: 2008. Crit Care Med 2008; 36: 296-327.

11. Engel C, Brunkhorst FM, Bone HG, et al. Epidemiology of sepsis in Germany: results from a national prospective multicenter study. Intensive Care Med 2007; 33: 606-18.

12. Karlsson S, Varpula M, Ruokonen E, et al. Incidence, treatment, and outcome of severe sepsis in ICU-treated adults in Finland: the Finnsepsis study. Intensive Care Med 2007; 33: 435-43.

13. Padkin A, Goldfrad C, Brady AR, et al. Epidemiology of severe sepsis occurring in the first $24 \mathrm{hrs}$ in intensive care units in England, Wales, and Northern Ireland. Crit Care Med 2003; 31: 2332-8.

14. Harrison DA, Welch CA, Eddleston JM. The epidemiology of severe sepsis in England, Wales and Northern Ireland, 1996 to 2004: secondary analysis of a high quality clinical database, the ICNARC Case Mix Programme Database. Crit Care 2006; 10: R42.

15. Alberti C, Brun-Buisson C, Burchardi H, et al. Epidemiology of sepsis and infection in ICU patients from an international multicentre cohort study. Intensive Care Med 2002; 28: 108-21.

16. Silva E, Pedro MA, Sogayar AC, et al. Brazilian Sepsis Epidemiological Study (BASES study). Crit Care 2004; 8: R251-60. 